The Canadian Journal of Higher Education, Vol. XXIII-2, 1993

La revue canadienne d'enseignement supérieur, Vol. XXIII-2, 1993

\title{
Teaching Assistants in Canadian Universities: An Unknown Resource
}

\author{
SERGE J. PICCININ," ANDY FARQUHARSON, ${ }^{\dagger}$ \\ \& ELENA MIHU $\triangle$
}

\begin{abstract}
Teaching Assistants (TAs) play an important role in most major universities. Interest in the training and development of TAs has increased in recent years, particularly in the U.S.A. In Canada very little research has been conducted regarding the work and status of TAs. The study provides a portrait of TAs in Canadian universities: their number, roles, remuneration, preparation and training, and policies governing their duties and responsibilities. Many universities had only a limited knowledge of the number of TAs employed, their qualifications for the tasks they are assigned and their training and supervision. The need for improving TA experience is clear and the establishment of a National Clearinghouse of TA-related materials is proposed.
\end{abstract}

\section{Résumé}

Les auxiliaires d'enseignement assument un rôle important dans la plupart des établissements d'une certaine taille. Depuis plusieurs années, particulièrement aux États-Unis, on observe un intérêt marqué pour les questions liées à la formation et au développement des auxiliaires d'enseignement. Au Canada,

* University of Ottawa $\quad \dagger$ University of Victoria $\Delta$ University of Ottawa An earlier version of this paper was presented at the annual meeting of the Society for Teaching and Learning in Higher Education, held at McGill University, June, 1990. The authors express appreciation to the personnel in each responding institution for their cooperation in providing data for this study. 
cependant, peu de recherches ont été effectués sur leur travail et leur statut. Cette étude trace donc le portrait des auxiliaires dans les universités canadiennes et analyse leur nombre, leurs rôles, leur rémunération. leur apprentissage et leur formation, ainsi que les politiques déterminant leurs tâches et responsabilités. On observe que certaines universités ne possèdent que très peu d'information quant au nombre d'auxiliaires engagés, à leurs qualifications en regard des tâches assignées, leur formation et à leur supervision. De toute évidence, l'expérience de travail des auxiliaires d'enseignement doit être améliorée, et l'établissement d'un Centre national de documentation portant sur la question est proposé.

Teaching Assistants (TAs) play an important role in most major universities (Diamond \& Gray, 1987a). They are responsible for tutorials and some of the teaching in the first two years of most undergraduate programs. Diamond and Gray (1987a) estimated that from $30 \%$ to $50 \%$ of an undergraduate's contact hours in the freshmen and sophomore years at U.S. research universities is with teaching assistants.

Because of the increasing teaching role of TAs, interest in their training and development has increased in recent years, particularly in the USA. An extensive amount of research literature has been dedicated to TA training (Abbot, Wulff, \& Szego, 1989; Ervin \& Muyskens, 1982; Foster, 1986; Garner, Geitz, Knop, Magnam, \& DiDonato, 1987; LeBlanc, 1987; Nyquist. Abbott, \& Wulff, 1989; Puccio, 1988; Rava, 1987), to the special training needs of, and students' expectations from international TAs (Bailey and Hinofotis, 1984; Gaskill \& Brinton, 1984; Gunesekera, 1988; Rice, 1984), to TAs' concerns, and perceived needs (Reagan, 1988; Ronkowski, 1989), and to TAs' assessment and evaluation (Angelo \& Cross, 1989; Wood, 1988). The increasing interest in TAs is also reflected in well attended national conferences on TA training (Nyquist, Abbott, \& Wulff, 1989).

A teaching assistantship is a complex task since TAs have a wide range of duties (Nyquist, Abbott, and Wulff, 1989): they conduct quiz sections or laboratories for lecture courses, provide tutorial sessions, grade exams, review tests and answer questions, hold office hours, and, less frequently, hold total responsibility for courses.

In Canada very little research has been conducted regarding the number, roles, training and development of TAs. Only two published Canadian studies concerning TAs have been found in the literature (Martin. Marx, Hasell, \& Ellis, 1978; Marx, Martin, Ellis, \& Hasell, 1978), and these deal with the 
implementation and usefulness of a new TA instruction program. Nationwide surveys which would reflect an overall picture of the situation of TAs are almost nonexistent. Only one national study on TAs in US universities was found (Diamond and Gray, 1987a, 1987b), and no Canadian surveys. Findings from a national Canadian survey could provide valuable information on TA roles, training, development, and TA policies, which could have important implications for the future training and development of TAs nationwide, and ultimately for the quality of teaching in Canadian universities.

The purpose of this study was to provide a portrait of TAs in Canada: their number, roles, remuneration, preparation and training, and policies governing their duties and responsibilities. A survey of all major Canadian universities was conducted to answer these questions, and to reflect the current situation regarding TAs in Canadian universities.

\section{Method}

\section{Instrument}

The questionnaire used in the present survey was developed by the authors, based on the relevant literature, particularly the US studies by Diamond and Gray (1987a, 1987b), and the authors' own experiences as professors responsible for TA training. It is entitled "TA Development Practices at Canadian Universities," and contains 14 questions concerning graduate TAs. The questions were formulated as objective checklists, but after each question a place was reserved for comments. The last question asked for any additional comments the respondents might have regarding TAs.

\section{Procedure}

The survey was sent to 45 Canadian universities chosen from an AUCC listing so as to include all institutions considered most likely to use graduate TAs. Thirty-four universities participated in the survey, a response rate of approximately $76 \%$. Many of the institutions reported difficulty in tracking down the information requested. In at least one instance the official involved commented on his frustration at being unable to gather answers to the questions from within his institution. Of the 34 universities that responded, eight did not make use of TAs. The data are therefore based on the information provided by the 26 universities which completed the questionnaire fully or partially.

The response rate across provinces was uneven. Responses were received from all universities in three provinces (Alberta, Saskatchewan, and Prince Edward Island), and from most universities in five other provinces 
(British Columbia, Ontario, Quebec, New Brunswick, and Nova Scotia). No responses were received from universities in two provinces (Manitoba and Newfoundland). However, the data offer a good approximation of the TA situation in Canadian universities.

\section{Results}

In the analysis of the results, frequency distributions or means were calculated for each question. The total number of graduate TAs in the universities that did respond is 18.500 , representing approximately $28 \%$ of the total (full-time plus part-time) graduate student enrolment, or $48 \%$ of the full-time only. When the universities are grouped by size, small universities (fewer than 10,000 students) report an average of 70 TAs; medium-sized universities $(10,000-20,000$ students) report an average of approximately 580 TAs; and large universities (more than 20,000 students), an average of approximately 1100 TAs (Figure 1). Thus the composite ratio of TAs to total full-time students is 1 to 64 for small universities, 1 to 17 for medium universities, and 1 to 18 for large universities.

The questionnaire asked universities to report on graduate student TAs. Three institutions reported that they also used undergraduates as TAs; two of these were small universities. While small universities report a 1 to 64 ratio of graduate TAs, it could be that they make use of a number of undergraduate students to serve this function. Given that smaller universities tend to have fewer graduate students in proportion to undergraduate students, perhaps their need for TAs is met by using senior undergraduates.

A wide range of activities may be subsumed under the category of "Assistance to Teachers." These include assistance limited to the preparation of instructional materials, assistance with teaching in laboratory settings, teaching a section of a course under the direction of a faculty member, or complete responsibility for teaching and evaluation of students within a given course.

The various roles of TAs were broken down into Leading Discussions, Classroom Teaching, Lab Instruction, Grading and Other. The data were divided into two broad disciplinary categories. Humanities/Social Sciences and Science/Engineering (Figure 2). Very little classroom teaching is done by TAs (only $2 \%$ in the Humanities/Social Sciences, and none in Science/Engineering). Grading $(55 \%)$ and Discussion Leading $(35 \%)$ predominate in the Humanities/Social Sciences; whereas Lab Instruction (59\%) and Grading (29\%) are the most common TA activities in Science/Engineering. 


\section{MEAN NUMBER OF TAs}

(Total number of TAs reported $=18,500$ )

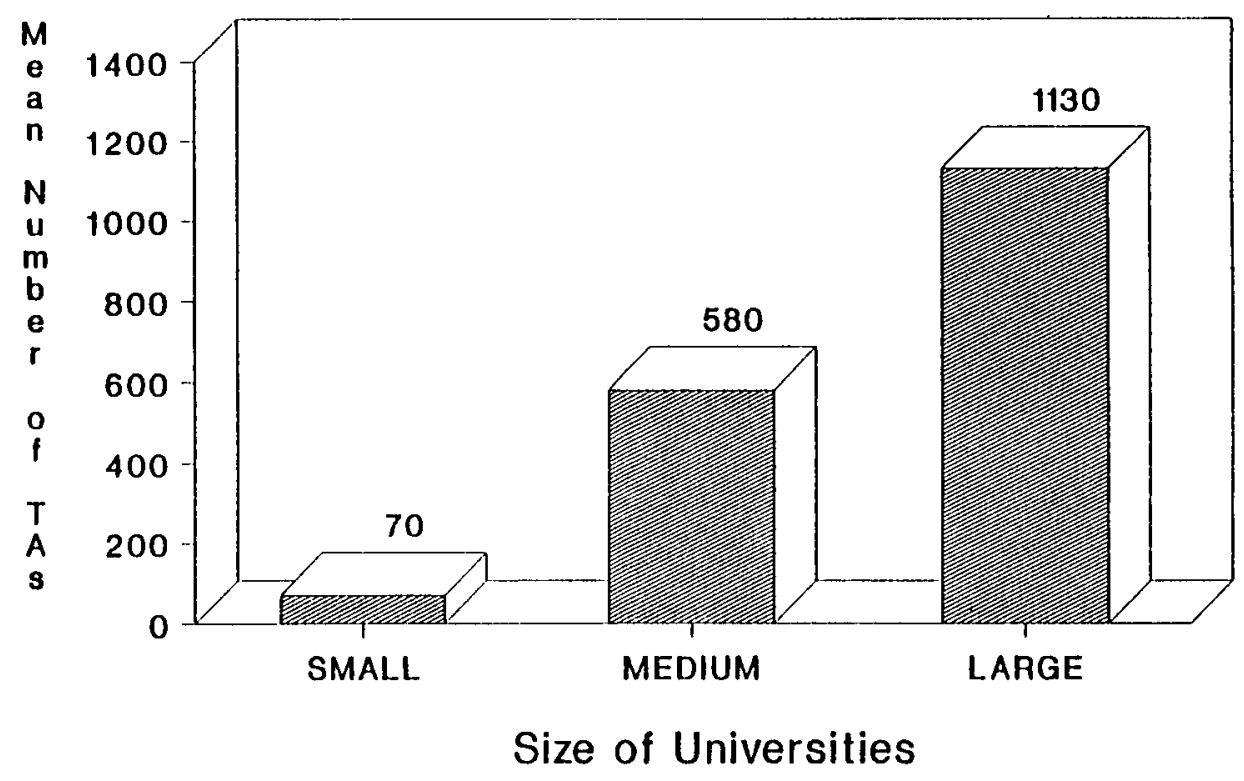

Figure 1 


\section{TIME ALLOCATION FOR TAS INSTRUCTOR SUPPORT}

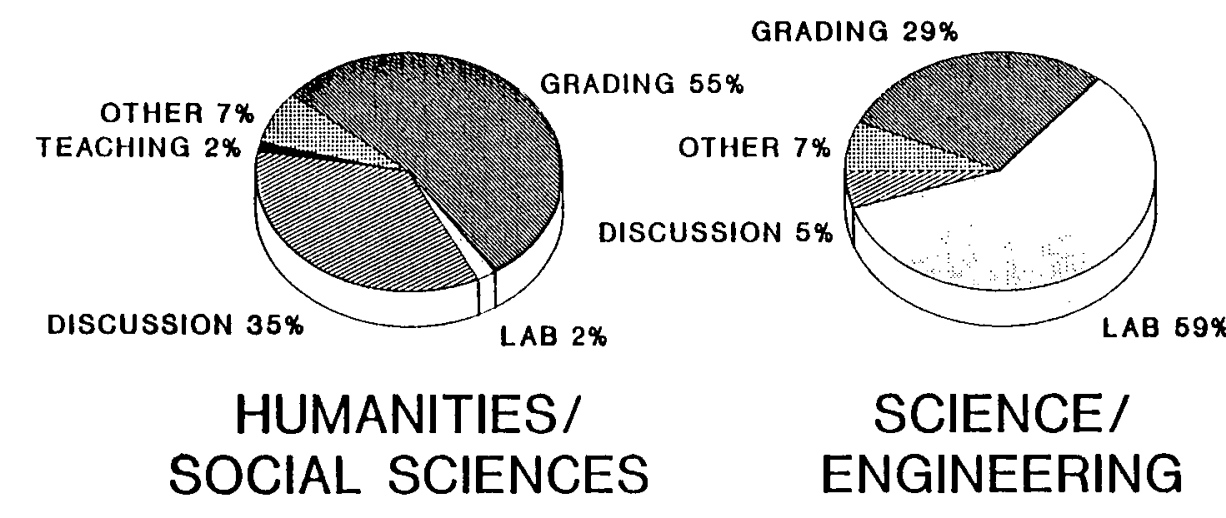

Figure 2 


\section{NUMBER OF HOURS WORKED}

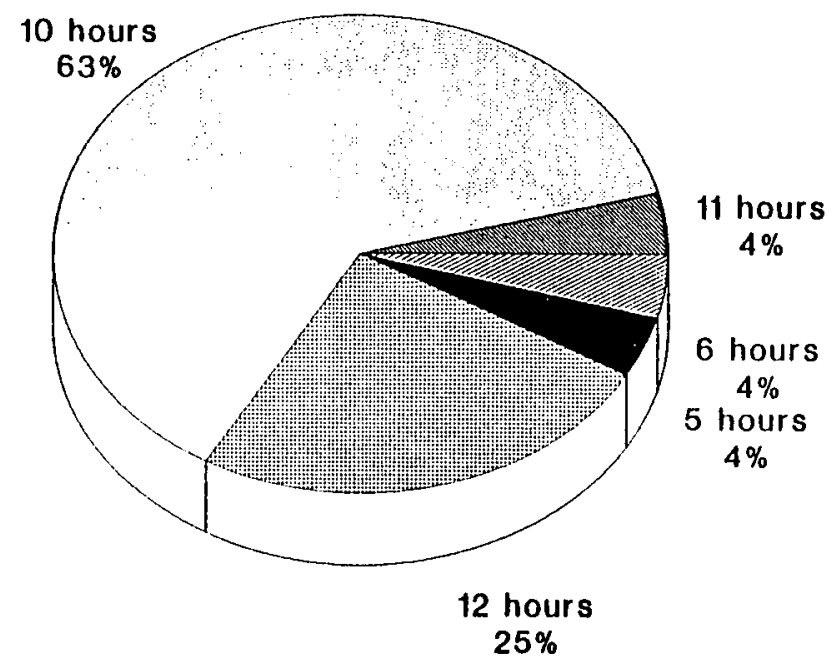

Figure 3 


\section{PAY RATES FOR TAs}

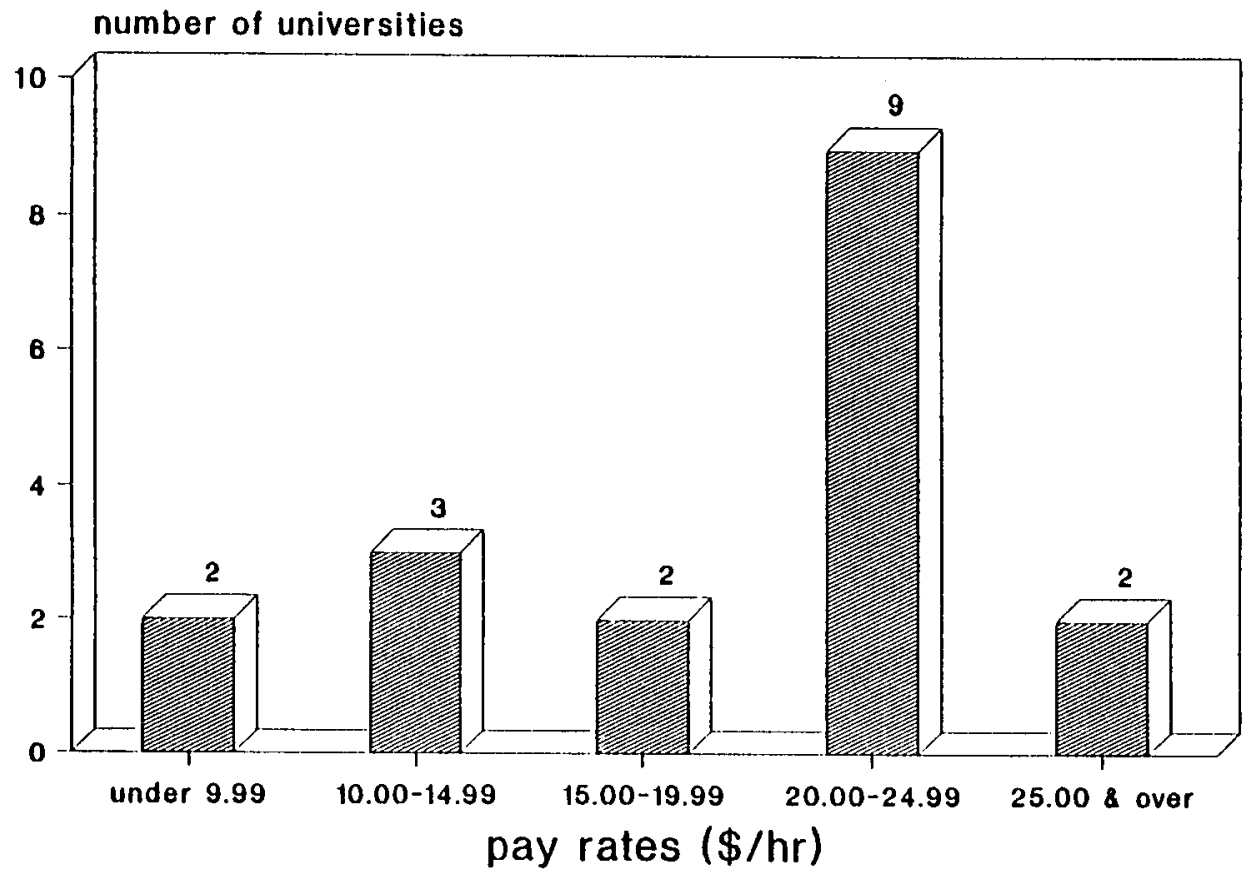

Figure 4 
It should be noted that some universities employ senior graduate students as part-time lecturers. This is clearly a different function from the teaching assistantship, and was not examined in this study.

The number of hours per week that TAs work was one of the more consistent characteristics across universities, with ten to twelve hours being typical (Figure 3). The hourly pay for TAs was much less consistent. Although the average pay per hour was close to $\$ 19$, the rates ranged from $\$ 9$ to $\$ 29$ (Figure 4). This amounts to a total of approximately $\$ 5000$ on average over two semesters. In general, rates of pay were higher in larger universities and in those where TAs were unionized.

Among the universities which responded to the survey, seven (approximately twenty seven percent) employed TAs who were unionized. The formalization of the role of TAs is evidenced by the fact that approximately seventy-three per cent of the responding universities have institutional, Faculty and/or Departmental level policies relating to the employment of TAs. These policies range from brief half page statements to lengthy, complex, collective agreements. Of the nineteen universities which have some type of policy, eleven forwarded some documentation along with their completed questionnaire.

Of the seven universities which reported having unionized $\mathrm{TAs}$, four appended the negotiated Collective Agreements. The two major unions involved in these agreements are the Canadian Union of Public Employees (CUPE) and the Canadian Union of Educational Workers (CUEW). The agreements are rather elaborate, having a length of 30 to 40 pages. They have very similar content, covering a number of major issues involved in a teaching assistantship, from management rights, work hours and pay rates to holidays, discipline and grievance procedures, and sexual harassment.

Seven of the remaining 14 non-unionized universities which reported having some form of TA policy attached documentation about their policies. Some of these documents cover only pay rates and working hours for TAs. Others also offer brief guidelines and regulations. The University of Calgary, for example, attached its thirteen page "Assistantship Schedule. Regulations, Guidelines, and Terms of Appointment. 1989-1990." The University of Windsor provided its more elaborate document, the "Employment Policy Manual. 1989-1990." This twenty page document includes paragraphs on most of the issues covered in the collective agreements of the universities with unionized TAs, but it is less detailed than the collective agreements.

The training of TAs for their instructional responsibilities was of particular interest to the research team. Approximately seventy-six percent of the 
responding universities have some type of training for TAs, but only twenty-eight percent have mandatory training. By and large this is of brief duration and includes a mixture of orientation and limited instructional training. For the most part the training is generic rather than specific, and there is little follow-up to improve teaching skills over time.

No differences were evident in the number of training hours, or type of training offered (mandatory, voluntary) between the unionized and non-unionized universities. Only two of the four collective agreements (one each of CUPE and CUEW) have a reference to TA training. No number of hours is specified and training is largely optional, except for TAs on their first appointment at York University. These are required to attend some mandatory training which is included in their paid hours.

The most popular type of training program held yearly at a number of universities is the "TA Day." The activities of TA Day, which in a few cases may involve two days, usually include a series of workshops covering various topics. The majority of these workshops are practical in nature, providing TAs with guidance for improving specific skills like conducting effective class discussions, evaluating student performance, helping students improve their writing skills, or making an effective presentation. Other workshops deal with the functions, responsibilities, roles and purpose of TAs, equity in the classroom, and the undergraduate students' perception of TAs.

The "TA Day-1989" at Brock University is an example of a typical one-day training program. Registration took place in the morning. After a half hour introductory session, eight complementary workshops of an hour and a half were offered, covering different topics. A short refreshment break was followed by a plenary session dealing with the general topic of sexual harassment. The eight workshops were repeated in the afternoon. TAs were invited to attend two workshops relevant to their instructional needs, one in the morning and one in the afternoon. Titles of the workshops included: "Leading more effective seminars," "Evaluating Essays," "Helping students develop good study skills," and "Introduction to learning styles: Veteran's Session."

Other universities (e.g., University of Waterloo) offer workshops for TAs throughout the first two weeks of the fall term, both university-wide and at a Department/Faculty level. Some universities, notably the University of Alberta, reported offering workshops for TAs throughout the academic year. The University of Guelph offers a six-session short course for graduate students, and McMaster University a series of mini-courses for TAs. The Instructional Development Centre of McMaster University also published in 1981 a 
Table 1

TA training in Canadian universities

Universities with training for TAs

Universities with mandatory training for TAs

Universities with training for international TAs

$12 \%$

Universities with person or unit responsible for training

$50 \%$

Universities which evaluate TAs

$21 \%$

catalogue of resources used in Canadian universities to help orient and train TAs. An updated edition of this catalogue is now in preparation.

Only twelve percent of the responding universities have any form of training specifically tailored for international (foreign student) TAs. No information was gathered on the proportion of TAs who were foreign students (Table 1).

Budgets for TA training are distinctly modest. The largest financial investment in TA training appeared to be at McGill University which currently earmarks approximately $\$ 10,000$ annually specifically for this purpose. However, to place this figure in context, one should know that Syracuse University, for example, invests more than $\$ 100,000$ in a required residential program for TAs; and one university in the American South-West is reputed to spend $\$ 300,000$ on TA training. Clearly, Canadian universities are not investing much in the way of money or time in the training of TAs. One can only wonder what the impact would be if institutions devoted even $2 \%$ of their budget allocation for TAs' salaries to training them for their roles. Approximately half the universities which responded identified a specific person or administrative unit with responsibility for TA training; it appears that for the most part this is generic training for TAs across the disciplines.

On the matter of TA evaluation, the bulk of universities report that they do not evaluate their TAs. Five universities (21\%) report a formal evaluation procedure for TAs. For the remainder, it appears that any evaluation of TAs is typically handled at a department level or is at best informal. One university reported that its collective agreement includes provision for both the formal and informal evaluation of TAs.

\section{Conclusions and Implications}

A number of conclusions may be drawn from this survey of practices at Canadian universities. First, TAs appear to be an unknown resource because many universities reported that the requested basic information on TAs was not 
immediately available, difficult to gather and typically not organized or centralized in any systematic manner. This becomes a matter of some concern when one considers that TAs play a major role vis- $d$-vis many students in their first year at university, and are therefore key players in the teaching/learning process. Furthermore, the number of TAs may well increase as enrolments rise. It is also important to recognize that, through the experiences they encounter as TAs, the professorate of tomorrow is socialized into the role of teacher in higher education. To the extent that we provide first rate training, support and supervision for TAs, they could be expected to be more effective faculty members in the future.

More comprehensive data are needed on the number of graduate and undergraduate TAs in our institutions, how they are selected, the responsibilities they carry, their rates of pay, their general working conditions and supervisory relationships, the manner in which they are evaluated and the identity of the people who will ensure their well-being and their instructional effectiveness. At the level of each institution, efforts need to be made to gather, organize, and centralize information on TAs as a basis for improving their selection, deployment. training and evaluation. The instrument developed for this study could be adapted for that purpose.

An important addition to an institutional study would be a canvass of the experience, opinions and suggestions of the TAs themselves. An earlier study by Ervin and Muyskens (1982) indicated that there were substantial differences between the learning needs identified by TAs themselves and those that were perceived by their supervisors.

An important suggestion derives from the range of materials on TA training and other TA issues that were submitted along with the responses to the survey. Clearly, much impressive work has already been done by certain universities, and by some faculties and departments in developing work protocols, designs for TA training, models for supervision, and TA evaluation forms. However, many people who are concerned with the effective use of TAs may be unaware of the volume of this material, where it is located and how it might be obtained. In the USA, a Task Force to explore the establishment of a National Clearinghouse of TA-related materials was established in 1989, and it took the next step of commissioning the development of materials that it felt were necessary but as yet unavailable. Those wishing to explore the idea of a National Clearinghouse on TA training in Canada are invited to contact the authors.

Among the benefits that might flow from this kind of collaborative approach would be an increased understanding of where human and material resources are located, as well as the potential development of more expensive 
types of generic training resources on a cost-shared basis. One example would be a series of trigger videotapes depicting problematic events that crop up in the day-to-day reality of the TA experience. Videotapes have been shown to be particularly helpful in effective and standardized TA training, but are expensive to produce.

A final consideration is that improving the TA experience may be the most important and accessible way to have a long-term impact on teaching improvement. It is clear that much needs to be done to expand and improve the quality of TA training as well as the evaluation of their contributions. Given a commitment to this agenda on the part of our institutions. significant strides can surely result. We may well be supported in these efforts by those who pay the tuition fees for undergraduate education - students, their parents and others. Those who pay the fees expect to find a qualified instructor in the laboratory or classroom and, at a minimum, effective TA training and evaluation may allay some of their concerns.

\section{References}

Abbott, R.D., Wulff, D.H., \& Szego, C.K. (1989). Review of research on TA training. New Directions for Teaching and Learning: Teaching Assistant Training in the 1990s, 39, 111-124.

Angelo. T.A., \& Cross, K.P. (1989). Classroom research for teaching assistants. New Directions for Teaching and Learning: Teaching Assistant Training in the 1990s, 39, 99-108.

Bailey, K.M., Hinofotis, F.B. (1984). A one-day workshop in oral communication skills. In K.M. Bailey, (Ed.), Foreign Teaching Assistants in U.S. Universities. Washington. DC: National Association for Foreign Student Affairs.

Diamond, R.M., \& Gray, P.J. (1987a, January). National study of teaching assistants. Syracuse, NY: Syracuse University Center for Instructional Development.

Diamond. R.M., \& Gray, P.J. (1987b, November). A national study of teaching assistants. Paper presented at the annual meeting of the Association for the Study of Higher Education, Baltimore, Maryland.

Ervin, G., \& Muyskens, J.A. (1982). On training TAs: Do we know what they want and need? Foreign Language Annals, 15, 335-344.

Foster, D. (1986). Training writing teachers in a small program. Writing Program Administration Journal, 10, 43-50.

Garner, L.C., Geitz, H., Knop, C., Magnam, S.S., \& DiDonato, R. (1987). Improving training of teaching assistants through inter-departmental cooperation. University of Wisconsin-Madison.Gaskill, W., \& Brinton, D. (1984). A one-week language skills orientation program for foreign teaching assistants and graduate students. In K.M. Bailey, (Ed.), Foreign Teaching Assistants in U.S. Universities. Washington, DC: National Association for Foreign Student Affairs. 
Gunesekera. M. (1988, March). The foreign teaching assistant and the office hour. Paper presented at the Annual Conference of the Teachers of English to Speakers of other Languages, Chicago, IL.

LeBlanc, L.B. (1987). Training for language teachers: A model program. College Teaching, 35, 19-21.

Martin, J., Marx, R.W., Hasell, J., \& Ellis, J.F. (1978). Improving the effectiveness of university teaching assistants: Report II. Canadian Journal of Education, 3, 13-26.

Marx, R.W., Martin, J., Ellis, J.F., \& Hasell, J. (1978). Improving the instructional effectiveness of university teaching assistants: Report I. Canadian Journal of Education, 3, 1-12.

Nyquist, J.D., Abbott, R.D.. \& Wulff, D.H. (1989). The challenge of TA training in the 1990s. New Directions for Teaching and Learning: Teaching Assistant Training in the 1990, 39, 7-15.

Puccio, P.M. (1988, March). Graduate instructor representation in Writing programs: Building communities through peer support. Paper presented at the Annual,Meeting of the Conference on College Composition and Communication, St. Louis, MO.

Rava, S. (1987). Training teaching assistants. ADFL-Bulletin, 19, 26-27.

Reagan, S.B. (1988). Teaching TAs to teach: Show, don't tell. Writing Program Administration, $11,41-51$.

Rice, D.S. (1984). A one-semester program for orienting the new foreign teaching assistant. In K.M. Bailey, (Ed.), Foreign Teaching Assistants in U.S. Universities. Washington, DC: National Association for Foreign Student Affairs.

Ronkowski, S. (1989, November). Changes in teaching assistant concerns over time. Paper presented at the National Conference on the Training and Employment of Teaching Assistants, Seattle, WA.

Wood, P.H. (1988, August). Evaluation that improves teaching. Paper presented at the Graduate Student Orientation Program, Bowling Green, OH. 